\title{
INTERAÇÕES ECOLÓGICAS NA CAATINGA: UMA PROPOSTA DE SEQUÊNCIA DIDÁTICA UTILIZANDO SEMINÁRIOS E O APLICATIVO Kahoot
}

\author{
Danielle de Sousa Alves ${ }^{1}$ \\ Fabricyo Villa Verde Silva ${ }^{2}$ \\ Regina Lúcia Félix de Aguiar Lima ${ }^{3}$ \\ Elâine Maria dos Santos Ribeiro ${ }^{4}$
}

Resumo: As metodologias ativas são instrumentos que favorecem a participação mais efetiva dos alunos no processo de aprendizagem. Neste trabalho o objetivo foi propor uma sequência didática que promova a investigação sobre as interações ecológicas estabelecidas pelos componentes da biodiversidade da Caatinga, e assim sensibilizar os atores do universo escolar sobre a valorização da biodiversidade e dos serviços ecossistêmicos da Caatinga. Seminários e a plataforma Kahoot são as metodologias ativas que fazem parte da sequência didática proposta. O Kahoot é ferramenta promissora para avaliação de conhecimentos e também para dinamização na culminância da sequência didática.

Palavras-chave: Biodiversidade; Serviços ecossistêmicos; Educação Ambiental; Metodologias Ativas.

Abstract: Active methodologies are instruments that favour the effective participation of students in the learning process. In this work the objective was to propose a didactic sequence that promotes investigation on the ecological interactions established by the components of Caatinga biodiversity, and thus sensitize the school universe actors about the valorization of Caatinga biodiversity and ecosystem services.t. Seminars and Kahoot platform are active methodologies that are part of the proposed teaching sequence. The Kahoot platform stands out as a promising tool for knowledge assessment and also for dynamization at the culmination of the didactic sequence.

Keywords: Biodiversity; Ecosystem Services; Environmental Education; Active Methodologies.

\footnotetext{
${ }^{1}$ Universidade de Pernambuco, E-mail: danielle.sousa@upe.br. http://lattes.cnpq.br/9348125890380428

2Universidade de Pernambuco. E-mail: fabricyo.villa@upe.br. http://lattes.cnpq.br/4262393293662632

3Universidade de Pernambuco. E-mail: regina.aguiar@upe.br. http://lattes.cnpq.br/8549101690272163

${ }^{4}$ Universidade de Pernambuco. E-mail: elaine.ribeiro@upe.br. http://lattes.cnpq.br/3304685448889789
} 


\section{Introdução}

O Semiárido brasileiro, com cobertura vegetal predominante da Caatinga, tem um dos mais baixos índices de desenvolvimento social e econômico do país e sua população tem grande dependência dos recursos naturais do ecossistema (SILVA et al. 2010). Essa é uma das regiões semiáridas mais populosas do mundo, e a falta de sensibilização e consciência ambiental por parte da população tem levado a uma alta exploração dos recursos naturais desse ecossistema, o que tem contribuído para a degradação do seu capital natural (SILVA et al. 2010; SOUSA; HONÓRIO, 2020). "Entender essa relação dos seres humanos com o seu ambiente tem sido a motivação de muitos pesquisadores, particularmente no que se refere à forma como nos apropriamos da natureza" (ALBUQUERQUE; MELO, 2018, p. 40).

A Caatinga é o ecossistema brasileiro menos estudado e um dos mais afetados pela atividade antrópica. Muitas espécies de animais e plantas estão ameaçadas de extinção. A degradação ambiental desse ecossistema é resultado do uso indevido dos recursos naturais causada, principalmente, pelo extrativismo de recursos florestais e pela criação extensiva de animais (LEAL; TABARELLI; SILVA, 2003). Essas modificações nos habitats provocam perdas de espécies de plantas e animais com a redução de serviços ecossistêmicos básicos como, por exemplo, proteção do solo, polinização, dispersão de sementes e controle de pragas. Em função disso, a perda da biodiversidade pode comprometer processos essenciais e também ameaçar a sobrevivência humana (LEAL et al. 2018). Uma forma de conscientizar a sociedade sobre a importância da conservação da biodiversidade "é divulgar a importância das espécies em relação ao seu papel na prestação de serviços ecossistêmicos" (CARVALHO et al. 2020, p. 282) que são essenciais a humanidade. Segundo Tabarelli et al. (2018),

O futuro da Caatinga requer ações imediatas para que as pessoas e a natureza possam caminhar juntas, numa trajetória mais sustentável. Ou seja, uma sociedade que conserve a biodiversidade regional, seja próspera economicamente, promova inclusão e justiça social e desfrute de boa governança.

Por meio do conhecimento, de habilidades e de valores podemos aprender a ter uma melhor percepção sobre a nossa história no ambiente, entendendo os riscos que ameaçam a nossa existência, devendo sempre se voltar a caminhos para o bem comum. Não obstante, "a educação é um instrumento central para o progresso social' (SPIEL; SCHWARTZMAN, 2018, p.35). Em respeito à Educação Ambiental (EA) tem papel fundamental nesse progresso e deve ser entendida e incorporada pelos indivíduos como parte da sua cidadania, uma vez que vai além de ações que visam à proteção dos ecossistemas e das espécies, pois é um processo mais amplo e contínuo, 
envolvendo ressignificações e com a convergência de atitudes para a sustentabilidade. Por definição, a EA está relacionada aos aspectos sociais, éticos, econômicos, culturais e políticos (BRASIL, 1999). A Base Nacional Comum Curricular (BNCC), no Bloco Ciências da Natureza e suas Tecnologias no Ensino Médio, traz algumas reflexões e competências na área da EA em que se deve "atribuir importância à natureza e a seus recursos, considerando a imprevisibilidade de fenômenos, as consequências da ação antrópica e os limites das explicações e do próprio conhecimento científico" (BRASIL, 2018, p. 556).

Muito se discute sobre a sustentabilidade como o caminho para o bem de todos, portanto, é muito importante também envolver de forma ativa e reflexiva atores do universo educativo os tornando protagonistas para transformação do ser cidadão, e este poder transformar a sociedade. No ambiente escolar, o educador, juntamente com a equipe pedagógica, pode realizar um planejamento participativo para que a EA seja vivenciada pelos alunos durante toda sua formação, podendo desenvolver projetos em parceria com as universidades. Todavia há uma necessidade de contextualização da EA sob uma visão holística, como soma de componentes das diferentes áreas de conhecimento, e não apenas como uma disciplina desconexa das demais, para que ela tenha um significado real (JACOBI, 2003; SANTOS; COSTA, 2015).

Nessa perspectiva, as metodologias ativas de ensino como, por exemplo, projetos, estudos de caso, sala de aula invertida e aprendizagem baseada em problemas e em jogos (GIL, 2020) apresentam-se como métodos que favorecem a aprendizagem, permitindo o estímulo de uma comunicação mais interativa e de maior aproximação do aluno aos conhecimentos. $O$ objetivo principal não é apenas transferir conhecimento, mas também de possibilitar aos professores um ensino de forma mais conectada com o mundo para que aprendam de forma mais atrativa e efetiva (FREIRE, 1996). Além disso, essas abordagens caracterizam-se por serem mais centralizadas no estudante e podem incentivar a criatividade e um desenvolvimento mais crítico e atuante, competências tão necessárias no mundo atual, frente às problematizações propostas (NASCIMENTO; FEITOSA, 2020).

Dessa forma, este trabalho tem por objetivo apresentar uma sequência didática sobre a importância da valorização da biodiversidade da Caatinga com base no conhecimento das interações ecológicas e dos serviços ecossistêmicos prestados, bem como introduzir a discussão sobre o pagamento pelos serviços ambientais para o bem-estar humano e ambiental; isto é, o caminho para a sustentabilidade. Essa sequência didática inclui o uso de estratégias de metodologias ativas, como seminário e o aplicativo Kahoot. 


\section{Valorização das interações entre fauna e flora da Caatinga para manutenção dos serviços ecossistêmicos}

Para se estabelecer um desenvolvimento lógico acerca da importância da preservação do capital natural da Caatinga, antes, serão expostos alguns conceitos e classificações importantes. Posteriormente, serão discutidas algumas ações de preservação e conservação da biodiversidade da Caatinga, bem como sobre o pagamento pelos serviços ambientais como um instrumento para a sustentabilidade.

O capital natural da Terra é tudo o que é formado pelos recursos naturais mais os serviços ecossistêmicos. Há uma infinidade de recursos naturais que basicamente são: o ar, a água, o solo, a terra e a biodiversidade. Em outra perspectiva, podem ser classificados como recursos renováveis, regulados por processos naturais, como acontece no ciclo da água potável, ou em recursos não renováveis, que podem se esgotar, por exemplo, os combustíveis fósseis (MILLER JÚNIOR, 2012).

Os serviços ecossistêmicos mantêm a economia e a vida do planeta e são todos os serviços e bens que a natureza nos fornece por meio dos processos e das relações ecológicas, por exemplo, água doce, ar puro, qualidade e renovação do solo, reciclagem de nutrientes, tratamento de resíduos, regulação do clima, polinização, produção de alimentos e produtos florestais, controle populacional e de pragas etc. e que garantem nossa sobrevivência e bem-estar (FERRAZ et al. 2019). Dessa forma, os componentes e os processos dos ecossistemas só ofertam serviços ecossistêmicos quando estes forem desfrutados diretamente ou indiretamente pelos humanos (VENDRAMINI et al. 2015). Há também outra discussão em respeito aos serviços ambientais, eles também representam serviços prestados pela natureza, mas com a interferência humana, por exemplo, restauração de ambientes em degradação, manejos conservacionistas etc. que acabam convergindo em serviços ecossistêmicos (TÔSTO; PEREIRA; MANGABEIRA, 2012).

A Caatinga ocorre no semiárido brasileiro, possui como aspectos naturais uma variedade de paisagens dado à complexidade das condições edafoclimáticas, hidrológicas e até mesmo da própria ação antrópica, o que contribuiu para a distribuição e variedade de suas espécies e na dinâmica dos seus ecossistemas (BASTOS; CORDEIRO, 2012). Segundo Fernandes e Queiroz (2018), a vegetação da Caatinga ocorre de forma fragmentada apresentando características de arbóreas a arbustivas, mas que ganha grande vigor nos curtos períodos de estiagem, contrastando com a vastidão seca demasiadamente manifestada. A Caatinga apresenta espécies que são localmente restritas e abundantes, além de adaptadas ao clima, fator associado, justamente, a alternância entre os períodos secos e úmidos (TABARELLI et al., 2018; GARDA et al. 2018). Por apresentar uma grande riqueza de linhagens endêmicas e muito distintas entre si, essa 
heterogeneidade traz grandes desafios para a conservação da sua biodiversidade (FONSECA et al., 2018; TABARELLI et al., 2018;).

A fauna da Caatinga também apresenta diversidade de endemismos com espécies ameaçadas de extinção dado o tráfico ilegal de animais, mudanças climáticas, uso da terra, construções humanas (ALBUQUERQUE; MELO, et al., 2028; GARDA et al., 2018). Possui um número expressivo de vertebrados, acreditando-se que ainda há muitas espécies a serem descobertas. Dentre as espécies de mamíferos com registro de ocorrência no ecossistema, 71\% são de roedores e morcegos (GARDA et al., 2018). Os registros para ictiofauna feitos entre os anos de 2003 e 2017 tiveram o maior incremento em riqueza de espécies. Só a partir do ano de 2006 foi que 16 das 20 espécies de anfíbios endêmicos existentes foram descritas (GARDA et al., 2018). A exploração de áreas de ecótono ou de ilhas úmidas da Caatinga revelou quase $50 \%$ a mais em diversidade de répteis, principalmente de lagartos. $O$ grupo das aves possui a maior riqueza, são 509 espécies descritas (SILVA; LEAL; TABARELLI, 2017; GARDA et al., 2018; BRASIL, 2019).

As relações ecológicas estabelecidas entre a fauna e a flora da Caatinga, ou entre outros componentes da biodiversidade do ecossistema, desempenham funções de vital importância para a região como, por exemplo, abelhas e formigas que são responsáveis pela reprodução da vegetação remanescente, bem como de algumas culturas agrícolas (SILVA et. al., 2010). Dos produtos florestais "há cerca de 390 espécies de árvores e ervas usadas para fins medicinais" (ALBUQUERQUE; MELO, 2018, p. 41). A mesofauna edáfica (rizosfera, endofíticos etc.), ainda pouco conhecida, atua na ciclagem de nutrientes, desenvolvimento de plantas, estruturação dos solos e fluxo da água, degradação de agrotóxicos, em manejos sustentáveis ambientais para o sequestro do carbono e conservação da biodiversidade, entre outras funções (BROWN et al., 2015), além de ter grande potencial como fonte de compostos bioativos de interesse agrícola e medicinal para a Caatinga.

Os componentes menos conhecidos dos ecossistemas, como fungos e bactérias, também podem estabelecer relações ecológicas importantes. Os fungos são um grupo com componentes importantes nos ecossistemas, pois de um modo geral tem função de decompositores nos ecossistemas, e contribuírem para a ciclagem biogeoquímica. Além disso, podem estabelecer relações simbiônticas ou harmônicas com outros componentes dos ecossistemas, e cumprir outras funções além da decomposição (ESPOSITO; AZEVEDO, 2010; LIMA et al., 2013; MAIA, 2014). As bactérias também podem tanto atuar, juntamente com os fungos, para o processo de decomposição e mineralização da matéria orgânica quanto pode também estabelecer relações com animais (ruminantes), plantas (leguminosas e gramíneas) ou fungos (liquenícolas) e prestar serviços ecossistêmicos importantes nessas interações (FIGUEIREDO, et al., 2013; BARBOSA-SILVA, et al. 2019).

Em seu contexto histórico evolutivo a Caatinga sempre foi marcada pelo preconceito, sendo associada a um ambiente inóspito e de pobreza, dado 
as condições climáticas. Sua população depende "dos recursos da sua biodiversidade para sobreviver, tais como: alimentação, remédios, forragem para os mais variados tipos de rebanhos, madeira para construções, entre outros" (LOIOLA; ROQUE; OLIVEIRA, 2012, p.17). Devido à escassez de dados sobre sua real biodiversidade, à pressão antrópica com 0 uso insustentável dos seus recursos naturais, de aspectos políticos e ainda do despreparo da população, a Caatinga tem sido degradada e considerada como um dos ecossistemas mais ameaçados do Brasil (TEIXEIRA, 2016).

Conforme o último relatório publicado pela Plataforma Intergovernamental sobre Biodiversidade e Serviços Ecossistêmicos (IPBES), a demanda por recursos naturais mais que dobrou nos últimos 50 anos, o que é proporcional ao crescimento populacional. Estima-se que $75 \%$ das cultivares globais dependem da polinização e $23 \%$ das áreas já foram degradadas, implicando na perda de potencial produtivo dessas áreas. Dessa forma, a produção agrícola está sob risco, o que só aumenta a insegurança alimentar (IPBES, 2019). No cenário regional da Caatinga, os investimentos em tecnologias de convivência com o semiárido e programas do governo, por exemplo, o bolsa família, Programa 1 milhão de cisternas (P1MC), têm permitido "melhores padrões de segurança alimentar e persistência das populações rurais, permitindo uma adaptação maior às mudanças climáticas e com menores impactos sobre a biota regional" (BPBES, 2019, p.114).

Tabarelli e Silva (2003) apresentam um estudo com a identificação de áreas prioritárias na Caatinga que teve como objetivo maior nortear planos de preservação e uso sustentável dos seus recursos naturais, com diversas estratégias e recomendações, incluindo planos de manejo da fauna e flora. Apontam soluções voltadas também para a inserção da EA e duas delas incluem "desenvolver e implantar programas de educação ambiental integrado às escolas e as associações rurais" e "criar bancos de dados sobre experiências de educação ambiental na Caatinga" (p. 791). As unidades de Conservação (UCs) também são muito importantes para a conservação da biodiversidade e seus serviços, além de permitirem o desenvolvimento regional econômico por meio do turismo, entre outros benefícios. Recentemente, duas UCs na Caatinga foram criadas recentemente na região do Boqueirão da Onça (BOFF, 2018).

Dado o exposto, deve-se considerar que a biodiversidade da Caatinga apresenta um patrimônio biológico de valor incalculável havendo necessidade de se conhecer sobre suas potencialidades. Para alcançarmos as metas de desenvolvimento sustentável, que têm como pilares fundamentais a garantia da sustentabilidade e erradicação da pobreza, é muito importante entender que a biota desempenha algumas funções importantes para redução dessas vulnerabilidades, no que se refere aos desastres econômicos, sociais e ambientais. A inserção da EA para convivência com o semiárido pode possibilitar o desenvolvimento sustentável da região, visto que há uma grande relação do homem com seu meio. Assim, é necessário estabelecer uma 
compreensão acerca dos significados do elo ecologia-sociedade para avaliar, gerir, restaurar e manter os recursos tanto naturais como humanos.

Fisher, Turner e Morling (2009) elencam conceitos relacionados aos serviços ecossistêmicos, apresentando, também, algumas classificações, que devem ser concebidas conforme a finalidade do estudo, para a estruturação de esquemas lógicos, para direcionamentos mais específicos de pesquisas; para a tomada de decisões etc. Conforme os modelos conceituais apontados por esses autores e, a partir do referencial temático apresenta-se de forma ampla exemplos de serviços ecossistêmicos promovidos por interações ecológicas entre a fauna e a flora da Caatinga (Quadros 1 e 2).

Quadro 1: Serviços ecossistêmicos envolvendo algumas interações entre fauna e flora da Caatinga.

\begin{tabular}{|c|c|c|c|c|}
\hline \multicolumn{3}{|c|}{ Componentes ecossistêmicos } & \multirow{2}{*}{$\begin{array}{l}\text { Serviços ecossistêmicos } \\
\text { diretos e/ou indiretos }\end{array}$} & \multirow{2}{*}{$\begin{array}{l}\text { Bem-estar } \\
\text { produzido }\end{array}$} \\
\hline Ambiente & Plantas & Animais & & \\
\hline $\begin{array}{l}\text { Áreas de } \\
\text { floresta } \\
\text { nativa }\end{array}$ & $\begin{array}{l}\text { Plantas com } \\
\text { flores ou } \\
\text { frutos de } \\
\text { modo geral }\end{array}$ & $\begin{array}{l}\text { Abelhas } \\
\text { Vespas } \\
\text { Formigas } \\
\text { Moscas } \\
\text { Mosquitos } \\
\text { Borboletas } \\
\text { Mariposas } \\
\text { Besouros } \\
\text { Lagartos } \\
\text { Tartarugas } \\
\text { Aves } \\
\text { Mamíferos } \\
\end{array}$ & $\begin{array}{l}\text { Polinização e dispersão de } \\
\text { sementes. } \\
\text { Produção de alimentos, } \\
\text { biomassa, biocombustíveis, } \\
\text { fármacos etc. } \\
\text { Reprodução vegetal. } \\
\text { Manutenção da } \\
\text { biodiversidade e dos } \\
\text { ecossistemas. }\end{array}$ & $\begin{array}{l}\text { Segurança } \\
\text { ambiental, } \\
\text { alimentar, } \\
\text { energética e } \\
\text { climática. } \\
\text { Saúde } \\
\text { humana. }\end{array}$ \\
\hline \multirow{2}{*}{$\begin{array}{l}\text { Áreas de } \\
\text { floresta } \\
\text { nativa ou } \\
\text { pastagens } \\
\text { em áreas de } \\
\text { Caatinga }\end{array}$} & \multirow[b]{2}{*}{$\begin{array}{l}\text { Pastagem ou } \\
\text { espécies } \\
\text { forrageiras }\end{array}$} & Ruminantes & Produção de carne e leite. & \begin{tabular}{|l} 
Segurança \\
alimentar. \\
Saúde \\
humana. \\
\end{tabular} \\
\hline & & $\begin{array}{l}\text { Ruminantes e } \\
\text { microrganismos } \\
\text { simbióticos }\end{array}$ & $\begin{array}{l}\text { Produção de gás de efeito } \\
\text { estufa que mantém a terra } \\
\text { aquecida permitindo a } \\
\text { manutenção da vida, } \\
\text { salientado o correto manejo } \\
\text { desses animais para a } \\
\text { evitar o excesso desses } \\
\text { gases. }\end{array}$ & $\begin{array}{l}\text { Segurança } \\
\text { ambiental e } \\
\text { climática. } \\
\text { Saúde } \\
\text { humana }\end{array}$ \\
\hline $\begin{array}{l}\text { Áreas de } \\
\text { floresta } \\
\text { nativa }\end{array}$ & $\begin{array}{l}\text { Plantas de } \\
\text { modo geral }\end{array}$ & Herbívoros & $\begin{array}{l}\text { Produção de metabólitos } \\
\text { secundários pelas plantas } \\
\text { em defesa à herbivoria. } \\
\text { O uso desses metabólitos } \\
\text { pode atuar na prevenção } \\
\text { de doenças, como câncer e } \\
\text { doenças cardíaca. }\end{array}$ & $\begin{array}{l}\text { Saúde } \\
\text { humana. }\end{array}$ \\
\hline
\end{tabular}

Fonte: Autoria própria, com base no modelo conceitual de Fisher, Turner e Morling (2009). 
Quadro 2: Serviços ecossistêmicos envolvendo interações estabelecidas por bactérias, algas e fungos da Caatinga.

\begin{tabular}{|c|c|c|c|c|}
\hline \multicolumn{3}{|c|}{ Componentes ecossistêmicos } & \multirow{2}{*}{$\begin{array}{c}\text { Serviços } \\
\text { ecossistêmicos } \\
\text { diretos e/ou } \\
\text { indiretos }\end{array}$} & \multirow{2}{*}{$\begin{array}{l}\text { Bem-estar } \\
\text { produzido }\end{array}$} \\
\hline $\begin{array}{l}\text { Seres } \\
\text { vivos }\end{array}$ & Ambiente & Interação & & \\
\hline \multirow{5}{*}{$\begin{array}{l}\text { Áreas de } \\
\text { floresta } \\
\text { nativa de } \\
\text { Caatinga } \\
\text { ou } \\
\text { Áreas } \\
\text { cultivadas }\end{array}$} & Plantas e fungos & $\begin{array}{l}\text { Mutualismo, } \\
\text { formando } \\
\text { micorrizas }\end{array}$ & $\begin{array}{l}\text { Ciclagem de } \\
\text { nutrientes e } \\
\text { transferência de } \\
\text { energia e matéria } \\
\text { para as plantas, } \\
\text { sucessivamente para } \\
\text { os demais seres } \\
\text { vivos da Terra. }\end{array}$ & \multirow{2}{*}{$\begin{array}{l}\text { Segurança } \\
\text { alimentar e } \\
\text { ambiental. }\end{array}$} \\
\hline & $\begin{array}{l}\text { Plantas e bactérias } \\
\text { diazotróficas }\end{array}$ & $\begin{array}{l}\text { Mutualismo, } \\
\text { com ou sem } \\
\text { formação de } \\
\text { rizóbio }\end{array}$ & $\begin{array}{l}\text { Fixação biológica de } \\
\text { nitrogênio e } \\
\text { solubilização de } \\
\text { fosfato para o } \\
\text { desenvolvimento da } \\
\text { planta. }\end{array}$ & \\
\hline & Plantas e fungos & $\begin{array}{l}\text { Mutualismo } \\
\text { entre plantas } \\
\text { e fungos } \\
\text { endofíticos }\end{array}$ & $\begin{array}{l}\text { Produção de } \\
\text { bioativos e produtos } \\
\text { naturais. } \\
\text { Biorremediação. }\end{array}$ & $\begin{array}{l}\text { Saúde humana. } \\
\text { Segurança } \\
\text { ambiental. }\end{array}$ \\
\hline & $\begin{array}{l}\text { Plantas e fungos } \\
\text { entomopatogênicos }\end{array}$ & $\begin{array}{l}\text { Harmônica } \\
\text { entre plantas } \\
\text { e fungos que } \\
\text { parasitam } \\
\text { insetos que } \\
\text { atuam como } \\
\text { pragas na } \\
\text { agricultura, } \\
\text { sendo } \\
\text { positiva para } \\
\text { as plantas. }\end{array}$ & $\begin{array}{l}\text { Controle microbiano } \\
\text { de pragas. }\end{array}$ & $\begin{array}{l}\text { Segurança } \\
\text { ambiental. }\end{array}$ \\
\hline & $\begin{array}{l}\text { Fungos liquenícolas } \\
\text { e algas }\end{array}$ & $\begin{array}{l}\text { Mutualismo, } \\
\text { formando } \\
\text { liquens }\end{array}$ & $\begin{array}{l}\text { Bioindicadores de } \\
\text { poluição. }\end{array}$ & Saúde humana. \\
\hline
\end{tabular}

Fonte: Autoria própria, com base principalmente no modelo conceitual de Fisher, Turner e Morling (2009).

\section{Pagamento por serviços ambientais}

Infelizmente, "sob o ponto de vista de mercantilização da natureza, a ausência de referência econômica dos recursos e serviços ecossistêmicos é um fator que contribui ainda mais sua degradação" (JACOBI; SINISGALLI, 2012, p.1474). Há um impasse quanto ao pagamento pelos serviços ambientais (ações humanas para preservação do capital natural), já que para tal precisase valorizar os serviços ecossistêmicos (benefícios promovidos pela natureza para o bem-estar humano) (ELOY; COUDEL; TONI, 2013; KLAMT, 2017). Haja 
vista também, que as implicações econômicas têm prevalecido na tomada de decisão sobre o uso dos recursos naturais e mudanças nos ecossistemas poderão prejudicar as pessoas no futuro (MEA, 2005). Campanha et al. (2019), em uma das contribuições da Empresa Brasileira de Pesquisa Agropecuária (Embrapa), abordam sobre a importância desses serviços ambientais para a preservação dos recursos naturais quanto às práticas sustentáveis no sistema da agropecuária, por exemplo, mitigação dos gases de efeito estufa e favorecimento da polinização com a otimização de áreas e a diversificação de sistemas de produção, recuperação da biodiversidade para conservação do solo e dos recursos hídricos, evitar a perda de habitats e da desertificação, entre outras práticas.

A Política de Pagamento pelos Serviços Ambientais (PSA) foi implementada somente em 2019, fruto de velhas políticas como, por exemplo, o Novo Código Florestal brasileiro, e tem como objetivos principais beneficiar e conscientizar as pessoas para a prestação de serviços em prol da conservação ambiental com práticas sustentáveis (CARNEIRO; SOUSA, 2020).

O dilema entre 0 crescimento econômico $e$ as questões socioambientais fomentado, principalmente, pela falta de uma gestão mais eficaz por parte dos governos, incluindo também as práticas trade-offs, tornou dificultoso a implementação de uma política PSA por algum tempo (ELOY; COUDEL; TONI, 2013). Ressalta-se que a "gestão dos recursos naturais do planeta de forma que os trade-offs entre as necessidades crescentes da população global e a manutenção da saúde do ecossistema sejam evitados ou minimizados" determinará o prazo de vida aqui na Terra (KLAMT, 2017; GÓMEZ, 2019). Ainda sobre a política PSA,

O contexto brasileiro para tal política requer qualificações importantes, mas é pleno de oportunidades que, se bem aproveitado, uma política nacional de pagamento por serviços ambientais poderá constituir-se num instrumento estruturante (investimento em infraestrutura ecológica) de uma estratégia real de desenvolvimento sustentável' (SHIKI; SHIKI, 2011, p. 100).

\section{Metodologias ativas na educação básica}

As metodologias ativas têm suas bases no início do século $X X$, com as ideias e teorias de Jonh Dewey (1926), Decroly (1929), que foram corroboradas por Ausubel (1960) e Kilpatrick (1975). As ideias de Dewey e Decroly foram introduzidas no Brasil por Anísio Teixeira e Lourenço Filho, com o movimento Escola Nova, em 1930. Essas teorias contribuíram o desenvolvimento das metodologias ativas, com uma pedagogia dinâmica, centrada no discente, que participam ativamente do processo de aprendizagem para construção do conhecimento com protagonismo, autodidatismo, autonomia e engajamento (CAMARGO; DAROS 2018).

revista brasileira educação ambiental 
A questão das ferramentas de comunicação também pode ser incluída como instrumento para as metodologias ativas, com o uso de Tecnologias de Informação e Comunicação (TIC). Nesse campo, o uso de plataformas e de aplicativos voltados à educação também deve ser estimulado no ambiente escolar, associado às metodologias ativas. As tecnologias digitais são recursos que podem ter uso educativo, como ferramentas de suporte para a prática pedagógica. Esses recursos têm estado cada vez mais disponíveis e acessíveis na sociedade atual. Elas têm produzido impacto nas relações sociais e profissionais de modo geral e, no contexto da pandemia da COVID19, elas tiveram uma grande inserção no ambiente educacional em todos os níveis do ensino, onde têm contribuído para a aprendizagem significativa. (BACICH; MORAN, 2018).

As diversas metodologias ativas de aprendizagem disponíveis podem ser combinadas, integradas e utilizadas, em todos os níveis de ensino, buscando otimizar o aprendizado discente e viabilizar a abordagem dos conteúdos, nas diversas áreas do conhecimento. São apresentadas a seguir as estratégias de metodologias ativas e a ferramentas incluídas nessa proposta: 0 aplicativo Kahoot, seminário e sequência didática.

O Kahoot é uma plataforma de aprendizagem baseada em jogos onde é possível criar, compartilhar e executar jogos (KAHOOT, 2014). Ele é um programa de computador desenvolvido para processar dados eletronicamente, visando tornar a execução de atividades mais fáceis e menos demoradas. Dentro da grande variedade de aplicativos disponíveis, alguns têm sido utilizados como recursos pedagógicos com significativa contribuição no processo de aprendizagem, especialmente no ensino online (CAMARGO; DAROS 2018). O Kahoot tem sido testado no contexto educativo e seu uso recomendado para situações diversas, mas destaca-se o uso como instrumento avaliativo. Plataformas como o Kahhot podem ser utilizadas em conjunto com outras estratégias que fazem parte das metodologias ativas (BOTTENTUIT JUNIOR, 2017).

Os seminários podem ser utilizados como estratégias de metodologias ativas que podem ser utilizadas, tanto para fomentar o aprendizado ativo, quanto podem ser usadas como parte do processo avaliativo formativo. $O$ termo seminário está etimologicamente relacionado a semente, sementeira, vida ou ideias novas (MASETTO, 2010). O método de seminário envolve realização de tarefas de preparação e aplicação conceitual, podendo incluir avaliação, auto avaliação e avaliação entre pares. Envolve também relações interpessoais, e espera-se que os alunos apresentem alto grau de comprometimento individual com o trabalho de grupo, habilidades sociais importantes para serem desenvolvidas. A proposição de realização de seminários pode levar os discentes apresentar desempenho de aprendizagem superior ao que se obtém usando metodologias tradicionais. Os docentes podem ter vantagens derivadas pelo estabelecimento de relação educacional produtiva com os discentes e pela sensação de satisfação (percepção de sucesso) profissional (MASETTO, 2010; DEBALD, 2018). 
A sequência didática (SD) pode ser definida como um conjunto de atividades ordenadas, estruturadas e articuladas que visam o alcance de objetivos educacionais, que têm um princípio e um fim conhecidos pelos docentes e discentes (ZABALA, 1998). A construção de uma SD deve incluir uma contextualização, análises e discussão, que são processados para trazer aspectos e fatos mais profundos acerca de uma problemática. Por fim, a construção de novos conhecimentos será dada conforme as etapas somativas realizadas por meio da sistematização proposta e da significação dos temas discutidos. Para tanto, é necessário que o professor avalie os progressos efetivados no decorrer da execução da SD (ARAÚJO, 2013). A Figura 1 apresenta um esquema com as etapas de uma sequência didática, elaborado segundo Araújo (2013), em que apresenta proposta estratégica e interdisciplinar. Faz-se necessário uma abordagem inicial do tema central da sequência didática para deixar os estudantes a par dos desafios que decorrerão, alinhando-se às ideias dos alunos, para que as habilidades e competências objetivadas sejam construídas passo a passo e os resultados sejam alcançados. Assim, vale colocar em prática o debate para a avaliação dos conhecimentos que os alunos trazem para que possam se expressar sobre o tema, verificando também a complexidade do problema proposto (ROSEMBLAT, 2000).

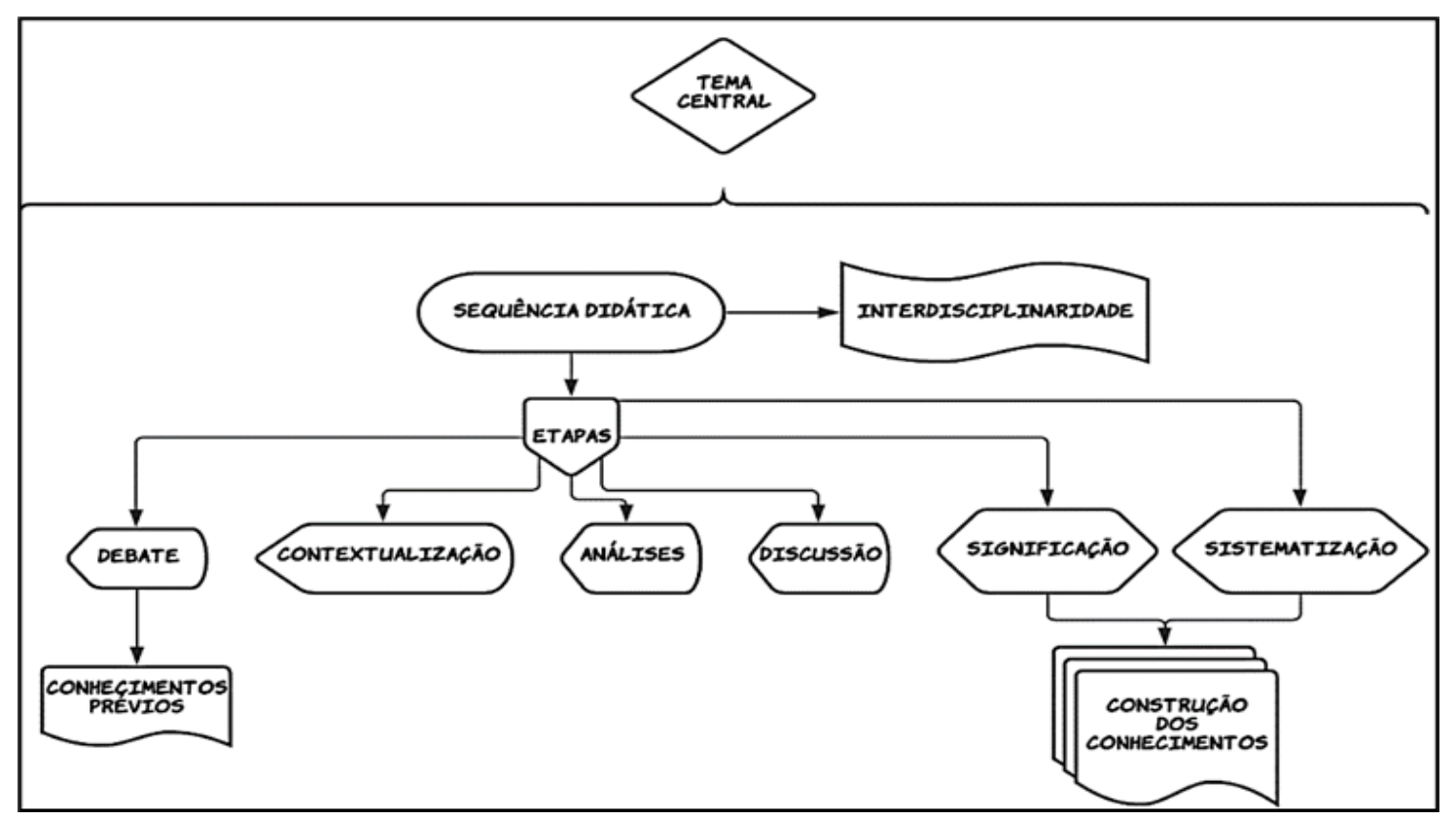

Figura 1: Esquema conceitual da sequência didática.

Fonte: Autoria própria, com base em Araújo (2013). 


\section{Metodologia}

Foi realizada inicialmente uma pesquisa tendo como tema as sequências didáticas. Como essa pesquisa discorre sobre um determinado problema, conceituando, classificando e compreendendo os fatos relacionados, então é caracterizada como de natureza descritiva (PAIVA, 2008). Assim, conhecendo adequadamente essa metodologia, poderá ser aplicada para o estudo do fenômeno da percepção humana sobre o ambiente Caatinga, quanto aos seus recursos naturais, as interações ecológicas entre fauna e flora e outros componentes da biodiversidade, os serviços ecossistêmicos prestados e uma discussão sobre como as ações antrópicas podem influenciar nessa dinâmica natural. Dessa forma, em paralelo, também se revisou o tema biodiversidade da Caatinga dentro do enfoque da Educação Ambiental.

Para a revisão sobre sequências didáticas e sobre a Caatinga, procedeu-se um estudo bibliográfico de caráter narrativo para dar um alicerce teórico que se correlaciona à proposta, considerando também que essa fundamentação situação-problema fosse clara e objetiva que pode nortear os trabalhos que serão desenvolvidos. Para tal, realizou-se buscas por artigos, relatórios e dados estatísticos no Google Scholar, em revistas e em sites (GIL, 2002).

Salienta-se que este estudo compõe um trabalho maior de tema geral "Aprendendo sobre o valor da biodiversidade da Caatinga e seus Serviços Ecossistêmicos no ensino escolar" apoiado pela Fundação de Amparo à Ciência e Tecnologia do Estado de Pernambuco (APQ - 0177-2.05/18). Portanto, a proposta da sequência didática faz parte de um conjunto de trabalhos que possuem como objetivo principal desenvolver jogos ou recursos didáticos para a valorização e aprendizagem sobre a Caatinga na educação básica, servindo de como material de apoio ao trabalho docente. A continuidade deste projeto se dará com a aplicação das propostas em escolas de ensino básico, o que não foi possível devido ao momento de pandemia causado pela doença COVID-19.

O público-alvo da sequência didática são alunos do Ensino Médio. Essa escolha teve como motivação maior a maturidade dos indivíduos para que seja realizada a proposta e para o estabelecimento de comunicação eficiente para a discussão sobre as temáticas. Para que este estudo fosse conduzido adequadamente, seguiram-se as seguintes etapas: (1) especificação do problema de pesquisa, que foi a escolha do eixo: valorização dos serviços ecossistêmicos promovidos pelas interações ecológicas entre fauna e flora da Caatinga; (2) levantamento de problemas; (3) pesquisa bibliográfica temática, para a fundamentação inicial; e (4) desenvolvimento da proposta, construção da sequência didática.

A pesquisa temática envolveu os seguintes tópicos: sequência didática; EA como instrumento para a construção da percepção ambiental; importância da preservação do capital natural como um caminho para a sustentabilidade e para o bem-estar humano; caracterização breve sobre a biodiversidade e os 
aspectos ambientais da Caatinga; e uma abordagem breve sobre a importância do pagamento pelos serviços ambientais; o uso do aplicativo Kahoot na educação. Posteriormente, após essa fundamentação teórica inicial, buscou-se base para a proposta também nas competências e habilidades estabelecidas na BNCC, e então se definiu o problema central da sequência didática, foram estabelecidos os objetivos e, por fim, feita a sistematização na forma de artigo.

\section{Resultados e Discussão}

Foi construída a sequência didática que tem como tema "Valorização da biodiversidade da Caatinga: caracterização dos serviços ecossistêmicos provenientes de interações entre fauna e flora" (Quadro 3).

Quadro 3. Sequência didática para promover a valorização da biodiversidade da Caatinga e dos serviços ecossistêmicos resultantes das interações entre fauna e flora no ensino médio.

Tema: Valorização da biodiversidade da Caatinga: caracterização dos serviços ecossistêmicos provenientes de interações entre fauna e flora.

Público-alvo: Ensino Médio.

Área do conhecimento: Educação Ambiental, Ciências Biológicas.

Introdução

A Educação Ambiental (EA) deve ser entendida e incorporada pelos alunos como parte da sua cidadania, uma vez que vai além das questões que visam à proteção dos ecossistemas e das espécies, pois também está relacionada aos aspectos sociais, éticos, econômicos e políticos. A EA no contexto da Caatinga deve ser abordada considerando todos esses aspectos. Também é interessante incluir metodologias ativas, como por exemplo, seminários e o aplicativos educacionais como o Kahoot.

\section{Habilidades da BNCC}

As habilidades relacionam-se conforme a escolha do público-alvo do Ensino Médio e do objetivo da sequência didática. São elas:

Discutir a importância da preservação e conservação da biodiversidade, considerando parâmetros qualitativos e quantitativos, e avaliar os efeitos da ação humana e das políticas ambientais para a garantia da sustentabilidade do planeta (EM13CNT206);

Identificar, analisar e discutir vulnerabilidades vinculadas às vivências e aos desafios contemporâneos aos quais as juventudes estão expostas, considerando os aspectos físico, psicoemocional e social, a fim de desenvolver e divulgar ações de prevenção e de promoção da saúde e do bem-estar (EM13CNT207) (BRASIL, 2018, p. 557).

\section{Objetivo}

Desenvolver nos alunos do ensino médio a percepção ambiental sobre o ecossistema Caatinga, considerando o ambiente natural, aspectos econômicos, políticos e culturais sob o enfoque da sustentabilidade, ressaltando a importância da biodiversidade da Caatinga e dos seus serviços ecossistêmicos. Por fim, compreender como as atividades antrópicas afetam o ambiente, os organismos e a própria humanidade.

\section{Desenvolvimento}

10 momento: Fomentar uma discussão crítica sobre a biodiversidade da Caatinga e a importância das relações ecológicas estabelecidas, bem como sobre as práticas ambientais voltadas para o equilíbrio ambiental e o desenvolvimento sustentável, levando-se em 
consideração a importância e os valores de uma sociedade ecologicamente responsável, economicamente viável, culturalmente diversa, politicamente atuante e socialmente justa. A questão do pagamento dos serviços ambientais. Apresentar estudos de cunho ambiental e contextualizados para a realidade da Caatinga que apresentem algumas interações ecológicas.

2- momento: Organizar os grupos, sortear os temas, definir os prazos e apresentar as orientações para produção dos seminários, que devem nortear-se para responder a seguinte pergunta: Quais as ações antrópicas a curto e a longo prazo que provocam a perda de serviços ecossistêmicos e o que poderá ser feito para mitigação e/ou adaptação dessas consequências?

\section{Temas dos Seminários:}

1. Interações entre plantas e animais: polinização e dispersão de sementes;

2. Interações entre plantas e animais: controle pragas e doenças;

3. Interações entre plantas e microrganismos: biorremediação;

4. Interações entre plantas e ruminantes: mitigação dos gases de efeito estufa e manejo adequado da terra;

5. Interações entre plantas e microrganismos (mutualismos): produção de compostos bioativos e produtos naturais.

6. Interações entre fungos e algas: líquens, seu papel na natureza e sua importância biotecnológica.

\section{Critérios conteúdistas para a elaboração dos seminários:}

- Quais as espécies da Caatinga estão envolvidas?

- Como está caracterizado o meio ambiente que envolve tais interações?

- Quais são os serviços ecossistêmicos (diretos e/ou indiretos) envolvidos? (discutir a

- $\quad$ sua importância para a população e a questão do pagamento de serviços ambientais).

- Quais fatores nas esferas ambiental, social, política e cultural afetam positivamente ou negativamente essas funções ecológicas? (apresentar dados estatísticos, por exemplo, sobre a degradação de terras; quais políticas estão implementadas na região; atuação de empresas, entre outras informações).

- Quais ações/serviços ambientais podem ser realizadas/promovidos para mitigação ou adaptação quanto às consequências provocadas pela perda dos serviços ecossistêmicos?

3 momento: Apresentação dos trabalhos produzidos pelas equipes, inclusive, deve-se promover incentivo à participação da comunidade escolar, por exemplo, uma feira de ciências, com o foco de envolver os atores do universo escolar para o desenvolvimento de responsabilidades para proteção e conservação do equilíbrio sustentável do meio ambiente.

40 momento: Dinâmica realizada com a plataforma digital Kahoot, preparadas pelos alunos de cada grupo e aplicada aos discentes dos demais grupos. Neste caso, será utilizado com a finalidade de revisar o conhecimento pós-seminários. Portanto, cada grupo deverá elaborar as questões conforme seu tema.

50 momento: Os professores podem divulgar os trabalhos desenvolvidos e seus produtos a fim de compartilhar o conhecimento acerca da realidade ambiental da Caatinga com respeito às interações ecológicas envolvidas para valoração dos serviços ambientais.

\section{Materiais e espaço}

Projetor de Slides, quadro, piloto, smartphones e Internet. Sala de aula e/ou outros espaços.

\section{Avaliação}

Apresentação e uso de recursos, questões relevantes abordadas, criatividade, insights e novos pontos de vista, apresentação de dados estatísticos sobre a realidade, domínio do assunto e exposição clara dos fatos. 
O foco da sequência didática no primeiro momento está na construção de conhecimento substancial, necessário para impulsionar os alunos na elaboração dos trabalhos, bem como na identificação de lacunas do conhecimento, hipóteses e avaliação dos desafios. Para isso, propõem-se encontros com a turma de alunos. Também, recomenda-se convidar palestrantes da área para fomentar uma discussão crítica acerca da importância das relações ecológicas, bem como das práticas ambientais voltadas para o equilíbrio do desenvolvimento sustentável da Caatinga. Além disso, é interessante apresentar projetos de cunho ambiental desenvolvidos na região (contextualização da realidade) para servir como inspiração para a elaboração dos trabalhos que serão desenvolvidos pelos grupos.

Em relação aos seminários, cada grupo será responsável por um tema, para conduzir as pesquisas e a apresentação. Nos Quadros 01 e 02, há informações que podem auxiliar o trabalho docente e o discente. Não menos importante, abordar as espécies que compõem a biodiversidade da Caatinga, dados estatísticos sobre a realidade, as problemáticas relacionadas ao contexto ambiental etc., tentando responder ao seguinte questionamento: Quais as ações antrópicas em curto e longo prazo que provocam a perda de serviços ecossistêmicos e o que poderá ser feito para mitigação e/ou adaptação dessas consequências? Os alunos deverão averiguar os fatores que afetam a oferta desses serviços pela natureza para nosso bem-estar, de acordo com o tema sorteado. Eles podem ser os riscos que ameaçam as espécies nativas, por exemplo, a introdução de espécies invasoras; as práticas insustentáveis de manejo do solo e da água, por exemplo, os desmatamentos, as queimadas, a irrigação incorreta que pode contaminar lençóis freáticos e aquíferos com o uso dos agrotóxicos; os subsídios determinados pelo governo que endossam práticas danosas ao meio ambiente em prol do viés econômico (trade-off), por exemplo, o uso de agrotóxicos para estimular a produtividade ao mesmo tempo que causa desequilíbrio ambiental, entre outros motores.

Assim, os alunos deverão apresentar em uma síntese qualitativa as possíveis soluções; aqui, pretende-se fortalecer que o espírito da cidadania não é somente estar a par sobre as questões ou problemáticas que nos rodeiam, mas também é pensar em medidas, principalmente, que estão ao alcance, para enfrentar as desigualdades, as adversidades, as injustiças, tendo a consciência de que é por meio de pequenas contribuições individuais e coletivas que se pode tornar o planeta Terra seguro do ponto de vista ambiental. Nesse contexto, também, pretende-se mobilizar toda a comunidade escolar, incluindo todos os atores desse universo, com a divulgação das experiências e compartilhamento dos resultados alcançados acerca da percepção ambiental da Caatinga, incluindo tais interações.

No momento da culminância da sequência didática, sugere-se a utilização da plataforma digital Kahoot, usando o recurso que se assemelha a um Quiz (jogo de perguntas e respostas), conforme exemplificado na Figura 2, com o objetivo de avaliar os conhecimentos construídos pelos estudantes nos seminários e para que seja consolidada a aprendizagem de todos. Sendo 
assim, cada grupo de trabalho, após a preparação do seminário, pode utilizar esse recurso para avaliar o conhecimento acerca dos outros alunos que estarão como plateia, por meio da elaboração de perguntas sobre o tema discutido pelo grupo.

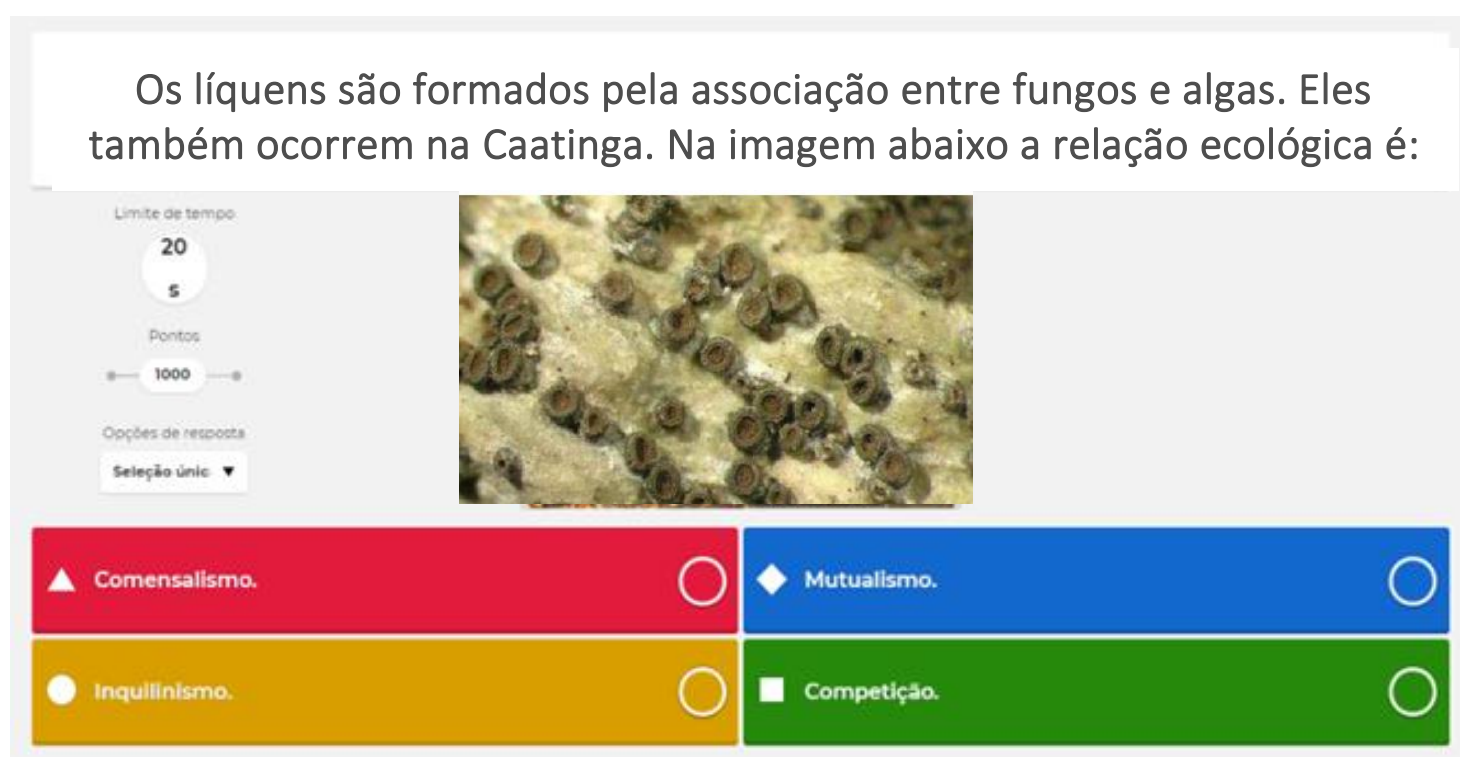

Figura 2. Quiz da plataforma Kahoot

Fonte: Elaborado pelos autores; Imagem de Reis 2015.

A avaliação será imprescindível no tocante à proposta. Portanto, indicase que se faça um levantamento de informações em todos os momentos, sempre verificando a concretização dos conhecimentos, se parcial ou total, e também para se adequar conforme a realidade, o que possibilitará o replanejamento das ações ou tomada de novos caminhos.

\section{Considerações Finais}

A sequência didática proposta é uma estratégia, que possibilita a abordagem de conhecimentos com relação às interações ecológicas na Caatinga e aos serviços ecossistêmicos. Ela cria oportunidades para que o estudante tenha um papel mais ativo no processo de aprendizagem. Além disso, pode permitir uma melhor compreensão sobre tópicos mais profundos do tema, na qual a aprendizagem pode se ressignificar diante da necessidade em apresentar uma resposta ao desafio colocado.

A realização das etapas da sequência didática possibilita aos estudantes o desenvolvimento de habilidades e competências presentes na BNCC, além de instigá-los a propor a resolução de problemas que façam parte das suas realidades. Esse aspecto é essencial para a construção da percepção do estudante enquanto cidadão em formação constante e também responsável pelo meio ambiente e pelo futuro. 
Quanto ao recurso lúdico Kahoot, considera-se interessante para o momento final da sequência didática, ou seja, para a avaliação dos conhecimentos obtidos no processo de realização da metodologia de seminários, pois contribuirá para a aprendizagem efetiva e significativa.

\section{Agradecimentos}

Ao Programa de Pós-graduação em Ciência e Tecnologia Ambiental (PPGCTA) da Universidade de Pernambuco Campus Petrolina.

À Coordenação de Aperfeiçoamento de Pessoal de Nível Superior (CAPES), Brasil - Código de Financiamento 001.

À Fundação de Amparo à Ciência e Tecnologia do Estado de Pernambuco (FACEPE) pela concessão de bolsas e financiamento do projeto "Aprendendo sobre o valor da biodiversidade da Caatinga e seus serviços ecossistêmicos no ensino escolar" (FACEPE APQ - 0177-2.05/18).

\section{Referências}

ALBUQUERQUE, U.P.; MELO, F.P.L. Socioecologia da Caatinga. Ciência e Cultura, v. 70, n. 4, p. 40-44, 2018.

ARAÚJO, D.L. O que é (e como faz) sequência didática? Entrepalavras, v. 3, n. 1, p. 322-334, 2013.

BARBOSA-SILVA, A.M.; SILVA, A.C.; PEREIRA, E.C.G.; BURIL, M.L.L.; SILVA, N.H.; CÁCERES, M.E.S.; APTROOT, A.; BEZERRA-GUSMẪO M.A.; Richness of lichens consumed by Constrictotermes cyphergaster in the Semiarid Region of Brazil. Sociobiology v. 66, n. 1, p. 154-160, 2019.

BASTOS, F.H.; CORDEIRO, A.M.N. Fatores naturais na evolução das paisagens no semiárido brasileiro: uma abordagem geral. Revista Geonorte, v. 2, n. 4, p. 464-476, 2012.

BRASIL. LEI № 9.795, de 27 de abril de 1999. Política Nacional de Educação Ambiental. 1999.

BRASIL. Ministério da Educação. Base Nacional Comum Curricular - BNCC, p. $600,2018$.

BRASIL. Saiba quais são as características da Caatinga. Fundação Joaquim Nabuco, 2019. Disponível em: <https://www.fundaj.gov.br/index.php/conselhonacional-da-reserva-da-biosfera-da-caatinga/9193-saiba-quais-sao-ascaracteristicas-da-caatinga>. Acesso em: 21 jun. 2019.

BOFF, M. Caatinga tem novas unidades de conservação. Ciência e Cultura, v. 70, n. 4, p. 57-57, 2018. 
BOTTENTUIT JUNIOR, J.B. O aplicativo Kahoot na educação: verificando os conhecimentos dos alunos em tempo real. Atas da $\mathbf{X}$ Conferência Internacional de Tecnologias de Informação e Comunicação na Educação. Challenges 2017: Aprender nas Nuvens (Learning in the Clouds). Braga, Portugal, 2017. p. 1587-1602.

BROWN, G.G. et al. Biodiversidade da fauna do solo e sua contribuição para os serviços ambientais. In: PARRON, L.M.; GARCIA, J.R.; OLIVEIRA, E.B.; BROWN, G.G.; PRADO, R.B. (Ed.). Serviços ambientais em sistemas agrícolas e florestais do Bioma Mata Atlântica. Brasília, DF: Embrapa, 2015.

BPBES. Plataforma Brasileira de Biodiversidade e Serviços Ecossistêmicos. São Carlos: Editora Cubo, 2019. Disponível em: $<$ https://doi.org/10.4322/978-85-60064-88-5>.

CAMPANHA et al. Cartilha Serviços ambientais e a agropecuária, Sete Lagoas: Embrapa Milho e Sorgo, 2019.

CARNEIRO, J.P.S.; SOUSA, J.S. Pagamento de serviços ambientais: uma análise sobre sua implantação. Revista Meio Ambiente e Sustentabilidade, v. 9, n. 18, 2020.

CARVALHO, W.S. et al. Formigas como provedoras de serviços ecossistêmicos na caatinga: como informar a sociedade sobre pesquisas ecológicas. Journal of Environmental Analysis and Progress, v. 5, n. 3, p. 281-287, 2020.

ELOY, L.; COUDEL, E.; TONI, F. Implementando Pagamentos por Serviços Ambientais no Brasil: caminhos para uma reflexão críticas. Sustentabilidade em debate, n. 4, p. 21-42, 2013.

FERNANDES, M.F.; QUEIROZ, L.P. Vegetação e flora da Caatinga. Ciência e Cultura, São Paulo, v. 70, n. 4, p. 51-56, 2018.

FERRAZ, R.P.D. et al. Marco Referencial em Serviços Ecossistêmicos. Brasília, DF: Embrapa, 2019.

FIGUEIREDO, M.V.B. et al. Tecnologias potenciais para uma agricultura sustentável. Recife: Ipa/Emater/Seagri-AL, 2013.

FISHER, B.; TURNER, R.K.; MORLING, P. Defining and classifying ecosystem services for decision making. Ecological Economics, v. 68, n. 3, p. 643-653, 2009.

FONSECA, C.R.; ANTONGIOVANNI, M.; MATSUMOTO, M.; BERNARD, E. VENTICINQUE, E. M. Oportunidades de conservação na Caatinga. Ciência e Cultura, v. 70, n. 4, p. 44-51, 2018.

FREIRE, P. Pedagogia da autonomia: Saberes necessários à prática educativa. 33ª Ed. São Paulo: Paz e Terra, 1996.

GARDA, A.A. et al. Os animais vertebrados do Bioma Caatinga. Ciência e Cultura, v. 70, n. 4, p. 29-34, 2018. 
GIL, A.C. Metodologia do Ensino Superior. $5^{a}$ ed. São Paulo: Atlas, 2020.

GIL, A.C. Como elaborar projetos de pesquisa. $4^{a}$ ed. São Paulo: Atlas, 2002.

GOMÉZ, C. Ecosystem services: the benefits people obtain from the planet's natural resources. IUCN Red List of Ecosystems, 2019. Disponível em: $<$ https://iucnrle.org/blog/ecosystem-services-the-benefits-people-obtain-fromthe-planets-natural-resources/>. Acesso em: 11 jul. 2020.

IPBES. Summary for policymakers of the global assessment report on biodiversity and ecosystem services of the Intergovernmental SciencePolicy Platform on Biodiversity and Ecosystem Services. Germany: 2019. https://doi.org/10.5281/zenodo.3553458.

JACOBI, P. Educação ambiental, cidadania e sustentabilidade. Cadernos de Pesquisa, n. 118, p. 189-205, 2003.

JACOBI, P.R.; SINISGALLI, P.A.A. Governança ambiental e economia verde. Ciência \& Saúde Coletiva, v. 17, n. 6, p. 1469-1478, 2012.

KAHOOT! Game-based blended learning \& classroom response system. 2014. Disponível em: <https://getkahoot.com>.

KLAMT, P.M.K. Política de pagamento por serviços ambientais (PSA): efetivação do direito fundamental ao meio ambiente ecologicamente equilibrado? In: VIII Seminário Internacional sobre Desenvolvimento Regional, 8., 2017, Santa Cruz do Sul. Anais... Santa Cruz do Sul, 2017.

LEAL, I.R.; TABARELLI, M.; SILVA, J.M.C. Ecologia e conservação da Caatinga. Recife: Editora Universitária da UFPE, 2003.

LEAL, I.R. et al. Interações planta-animal na Caatinga: visão geral e perspectivas futuras. Ciência e Cultura, v. 70, n. 4, p. 35-40, 2018.

LIMA, C. E. P. L.; SANTANA, A. S.; MERGULHÃO, A. C. E. S.; LIMA, R. L. F. A. Micorriza arbuscular: alternativa para uso na agricultura sustentável. In: FIGUEIREDO, M.V.B. et al. Tecnologias potenciais para uma agricultura sustentável. Recife: Ipa/Emater/Seagri-AL, 2013.

LOIOLA, M.I.B.; ROQUE A.A., OLIVEIRA A.C.P. Caatinga: vegetação do semiárido brasileiro. SPECO Sociedade Portuguesa de Ecologia, Lisboa, 2012.

MAIA, L.C. Fungos do Parque Nacional do Catimbau. Recife: Editora UFPE, 2014.

MEA - MILLENNIUM ECOSYSTEM ASSESSMENT. Ecosystems and human well-being: opportunities and challenges for business and industry. Washington, DC: World Resources Institute, 2005.

MILLER JÚNIOR, G.T. Ciência Ambiental. 14aㅡ ed. São Paulo: Cengage Learning, 2012. 
NASCIMENTO, J.L.; FEITOSA, R.A. Metodologias ativas, com foco nos processos de ensino e aprendizagem. Research, Society and Development, v. 9, n. 9, p. 1-17, 2020.

PAIVA, V.L.M.E. A pesquisa narrativa: uma introdução. Rev. Bras. Linguist. Apl., v. 8, n. 2, p. 261-266, 2008.

ROSEMBLAT, E. Critérios para a construção de uma sequência didática no ensino dos discursos argumentativos. In: Rojo, R. (Org.) A Prática de Linguagem em Sala de Aula: Praticando os PCNs. Campinas: Mercado de Letras, 2000.

SANTOS, T.C.; COSTA, M.A.F. Um olhar sobre a educação ambiental expressa nas diretrizes curriculares nacionais para a educação ambiental. Revista Práxis, v. 7, n. 13, p. 143-151, 2015.

SHIKI, S.; SHIKI, S.F.N. Os desafios de uma política nacional de pagamentos por serviços ambientais: lições a partir do caso do pró ambiente. Sustentabilidade em debate, v. 2, n. 1, p. 99-117, 2011.

SILVA, J.R. 2015. Liquens corticícolas crostosos em área de caatinga e brejo de altitude na Serra da Guia, Poço Redondo, Sergipe, Brasil. Dissertação (Mestrado em Ecologia). Programa de Pós-graduação em Ecologia e Conservação, Universidade Federal de Sergipe, Aracaju, SE. Disponível em: https://ri.ufs.br/bitstream/riufs/4431/1/JEANNE REIS SANTOS.pdf\#page=24

SILVA, P.C.G.S.; MOURA, M.S.B.; KIILL, L.H.P.; BRITO, L.T.L.; PEREIRA, L.A.; SÁ, I.B.; CORREIA, R.C.; TEIXEIRA, A.H.C.; CUNHA, T.J.F.; GUIMARÃES FILHO, C. Caracterização do Semiárido brasileiro: fatores naturais e humanos. In: SÁ, I. B.; SILVA, P. C. G. S. Semiárido brasileiro: pesquisa, desenvolvimento e inovação. Petrolina: Embrapa Semiárido, Embrapa Semiárido. Petrolina, 2010.

SILVA, J.M.C.; LEAL, I.R; TABARELLI, M. Caatinga: The largest tropical dry forest region in South America. Cahm: Springer International Publishing. Switzerland. 2017.

SPIEL, C.; SCHWARTZMAN, S. A contribuição da educação para o progresso social. Ciência \& Trópico, v. 42, n. 1, p. 31-106, 2018.

SOUSA, V.R.; HONÓRIO, M.S. Da degradação a preservação: o papel da educação ambiental na sustentabilidade da caatinga. Revista Brasileira de Direito e Gestão Pública, v.8, n.3, p.932-946, 2020.

TABARELLI, M.; LEAL, I.R.; SCARANO, F.R.; SILVA, J. M.C. Caatinga, legado, trajetória e desafios rumo à sustentabilidade. Ciência e Cultura, v.70, n.4, p.25-28, 2018.

TABARELLI, M.; SILVA J.M.C. Áreas e ações prioritárias para a conservação da biodiversidade da Caatinga. In: LEAL, I.R.; TABARELLI, M.; SILVA, J.M.C. Ecologia e conservação da Caatinga. Recife: Editora Universitária UFPE, 2003. p.777-796. 
TEIXEIRA, M.N. O sertão semiárido. Uma relação de sociedade e natureza numa dinâmica de organização social do espaço. Sociedade e Estado, v.31, n. 3, p. 769-780, 2016.

TÔSTO, S.G.; PEREIRA L.C.; MANGABEIRA J.A.C. Serviços ecossistêmicos e Serviços ambientais: conceitos e importância. Ecodebate, 2012. Disponível em: $\quad<$ https://www.ecodebate.com.br/2012/12/13/servicos-ecossistemicos-eservicos-ambientais-conceitos-e-importancia-artigo-de-sergio-gomes-tosto-

lauro-charlet-pereira-e-joao-alfredo-de-c-mangabeira/>. Acesso em: 18 jul. 2020.

VENDRAMINI, A. et al. Serviços Ecossistêmicos - Que bicho é esse ? p. 22, 2015. Disponível em: <http://www.p22on.com.br/2015/10/01/pdf-da-edicao-2/>. Acesso em: 12 jul. 2020. 